\title{
REPRESENTACÕES SOCIAIS DA VIOLÊNCIA NA VELHICE: ESTUDO COMPARATIVO ENTRE PROFISSIONAIS DE SAÚDE E AGENTES COMUNITÁRIOS DE SAÚDE
}

SOCIAL REPRESENTATIONS OF VIOLENCE IN OLD AGE: COMPARATIVE STUDY BETWEEN HEALTH PROFESSIONALS AND STAFF OF COMMUNITY HEALTH

\author{
Ludgleydson Fernandes de Araújo, Edilene Alves da Cruz e Romulo Araujo da Rocha
}

Universidade Federal do Piauí, Parnaiba, Brasil

\begin{abstract}
RESUMO
Objetivou-se identificar e comparar as Representações Sociais (RS) da violência na velhice entre Agentes Comunitários de Saúde (ACS) e os Profissionais de Saúde inseridos na Estratégia Saúde da Família (ESF). A amostra foi constituída por 100 participantes (50 ACS e 50 profissionais de saúde) de ambos os sexo (sendo $59 \%$ do sexo feminino e $41 \%$ do sexo masculino). Utilizou-se como instrumento um questionário sociodemografico e uma Entrevista Estruturada com quatro questões norteadoras acerca da violência contra o idoso, realizadas de forma individual. Utilizou-se na análise dos dados o software ALCESTE - Análise Lexical por Contexto um Conjunto de Segmentos de Texto (Reinert, 1990). Verificou-se nos dados obtidos tanto nos profissionais de saúde quanto nos ACS a visualização de casos de violência na velhice em sua pratica profissional. Estes atores sociais construíram suas RS da violência contra idosos ancoradas na presença de negligência, abuso e maus-tratos.
\end{abstract}

Palavras-chave: velhice; Programa Saúde da Família; representações sociais; violência.

\begin{abstract}
The objective was to identify and compare social representations (SR) of violence in old age among Community Health Agents (CHA) and the Health Professionals inserted into family Health Strategy (ESF). The sample consisted of 100 participants (50 CHA and 50 Healthcare Professionals) of both sexes (59\% female and $41 \%$ male). Used as an instrument socio-demographic questionnaire and an interview with four guiding questions about violence against the elderly, carried out individually. based on data studies in data analysis software ALCESTE - Lexical Analysis of a Set of Segments Context Text (Reinert, 1990). It was found in the data obtained both from health professionals in the CHA as the viewing of violence in old age in their practice professional. These social actors have built their SR of violence against the elderly based in the presence of neglect, abuse and mistreatment.
\end{abstract}

Keywords: elderly; Family Health Program; social representations; violence.

Nas últimas cinco décadas o envelhecimento populacional tem se tornado um fenômeno que atinge grande parte do mundo. Observa-se no âmbito brasileiro um processo de inversão da característica populacional estabelecida, isto é, houve uma diminuição das taxas de natalidade e mortalidade, ocasionando, com isso, o crescimento da população com idade de 60 anos ou mais (Ministério da Saúde, 2009).

Dentre os fatores que contribuíram para este processo de inversão, destacam-se a diminuição da fecundidade, acompanhada pelas grandes campanhas de planejamento familiar, a melhoria nutricional, os avanços médicos com acesso à assistência à saúde e melhores condições sanitárias (Araújo \& Lobo Filho, 2009; Fortes-Burgos, 2010).

Segundo a projeção do Instituto Brasileiro de Geografia e Estatística (IBGE, 2008), o Brasil continuará galgando anos na vida média de sua população, alcançando em 2050 o patamar de 81,29 anos, basicamente o mesmo nível atual da Islândia $(81,80)$, China $(82,20)$ e Japão $(82,60)$. Em escala mundial, a esperança de vida da população brasileira foi estimada, para 2008 (período 2005-2010), em 67,2 anos. Isto significa que para o período de 2045-2050 a população idosa brasileira terá crescido mais de $18 \%$ (IBGE, 2008). 
De acordo com os dados levantados pelo IBGE (2008), o índice de envelhecimento aponta para mudanças na estrutura etária da população brasileira. No ano de 2008, para cada grupo de 100 crianças de 0 a 14 anos existiam 24,7 idosos de 65 anos ou mais. Em 2050, estima-se que para o mesmo número de crianças de 0 a 14 anos existirão 172, 7 idosos. Com o aumento dessa população, a sociedade tem voltado sua atenção às questões políticas, econômicas, sociais e de saúde, procurando elaborar políticas sociais que venham garantir o atendimento na saúde pública e psicossocial, as quais se apresentam como dispositivos muito importantes de apoio para os idosos (Ministério da Saúde, 2009; Neri, 2009).

Ao mesmo tempo em que as relações interpessoais e familiares estão sendo interferidas, as relações sociais e comunitárias também têm sido afetadas, de modo que num arranjo familiar é raro não possuir um membro idoso. Diante disso, presenciamse comumente pessoas com idade de 60 anos ou mais sendo responsáveis economicamente pelos lares brasileiros (Araújo \& Lobo Filho, 2009; IBGE, 2008).

Contudo, o idoso ainda é rejeitado no decorrer da velhice por ser considerado improdutivo pela sociedade. Em consequência disso, na maioria das vezes tem sua autonomia comprometida e acaba se tornando dependente. Este é um dado importante, porque à medida que aumenta o grau de dependência do idoso, mais vulnerável aos maus-tratos e à violência ele passa a ficar (Araújo, Amaral, Sá, Azevedo, \& Lobo Filho, 2012; Araújo, Rocha, \& Cruz, 2012; Minayo, 2007; Neri, 2009; Santos, Silva, Carvalho, \& Menezes, 2007; Saraiva \& Coutinho, 2012).

Apesar de serem fenômenos não muito recentes, a violência e os maus-tratos na velhice se tornaram mais evidentes nas investigações científicas em meados da década de 1970, a partir da pesquisa realizada por Baker, enfatizando a violência intrafamiliar, especificamente o "espancamento de avós" (Faleiros, 2007). Na década seguinte, houve um aumento nas investigações científicas sobre o tema, tendo como objetivo o entendimento dos meandros biopsicossociais que compõem a violência e os maustratos contra os idosos (Faleiros, 2007; Machado \& Queiroz, 2006; Minayo, 2007).

Segundo Faleiros (2007), a violência é entendida como uma relação desigual de poder, implicando a negação do outro, da diferença, da tolerância e das oportunidades com impacto que se traduz em prejuízo, dano ou sofrimento e que infringe o pacto social da convivência, de garantia de direitos e de modo civilizatório fundado nos direitos humanos. A violência contra a pessoa idosa pode ser manifestada de várias formas, a saber: (a) A violência intrafamiliar, a qual é chamada de violência "calada" ou do silêncio, sendo praticada na maioria das vezes por filhos, netos, cônjuges, irmãos ou parentes próximos. Ela pode ser caracterizada pela violência física (relação de poder com impacto no corpo, que se traduz em marcas visíveis ou mesmo em morte); psicológica (relação de poder com uso da autoridade sobre o outro de forma inadequada); negligência (relação de poder que implica abandono, descompromisso do cuidado e do afeto); financeiro (relação de poder que implica a pressão sobre o outro para ceder dinheiro, cobrando com base em chantagens e abuso de confiança); e sexual (relação de poder pela força ou sedução, entre um agressor e uma pessoa vitimizada para satisfação sexual do agressor com submissão da pessoa vitimizada); (b) A violência Institucional, que é o tipo de relação existente nas instituições de longa permanência para idosos e instituições de serviço privadas e públicas, nas quais nega ou atrasa o acesso, hostiliza o idoso e não respeita sua autonomia; e (c) A violência sociopolítica, que se refere às relações sociais que envolvem grupos e pessoas consideradas delinquentes comuns e a estruturas econômicas e políticas da desigualdade nas relações de exclusão/ exploração/ periferização (Araújo et al., 2012; Araújo, Rocha, \& Cruz, 2012; Faleiros, 2004, 2007; Pinho, Custódio, \& Makdisse, 2009; Saraiva \& Coutinho, 2012).

De acordo com o Ministério da Saúde (2008), no Brasil, das 626 notificações de violências contra idosos atendidos em serviços de saúde de referência, 338 foram vítimas dos próprios filhos. O dado representa $54 \%$ das notificações de agressões a pessoas com 60 anos ou mais, dentro de casa. Entre os tipos de agressões, a violência moral ou psicológica foi a mais relatada (55\%), seguida da física $(27 \%)$, do abandono $(22 \%)$ e, por último, do dano financeiro ou patrimonial $(27 \%)$.

Foi observado também, tanto na literatura internacional quanto na brasileira, um elevado número de subnotificações em todo o mundo, além do fato de pesquisadores estimarem que $70 \%$ das lesões sofridas pelos idosos não estão nas estatísticas. Estes valores revelam apenas uma pequena porcentagem do total de idosos maltratados, sendo que em sua maioria eles zelam pela família e temem por si próprios e acabam deixando de procurar ajuda, contribuindo para que as situações de violência e maus-tratos permaneçam ocultas pelos envolvidos (Minayo, 2007; Ministério da Saúde, 2008; Santos et al., 2007).

Observando o cenário da saúde no Brasil, o Programa Saúde da Família, hoje nomeado por 
Estratégia Saúde da Família (ESF), concebido em 1994 como uma estratégia de reconstrução do modelo de atendimento em saúde, surge para aumentar a cobertura dos serviços através da reorganização da atenção básica, com foco no território e na promoção de saúde. Para exercer essa tarefa, é necessário que sua expansão se faça acompanhada por uma equipe de médicos, enfermeiros, auxiliares de enfermagem e Agentes Comunitários de Saúde (ACS). Através dessa estrutura, há uma abertura para a criação de vínculos de corresponsabilidade entre os profissionais e a população acompanhada, facilitando a identificação e o atendimento humanizado (Ministério da Saúde, 2008, 2009).

No tocante à realidade dos casos de violência e maus-tratos na velhice, o Ministério da Saúde tem contribuído consideravelmente através das equipes de Saúde da família (PSF) para a identificação destas situações. Os ACSs, por exemplo, dispõem de grandes informações sobre esses casos, haja vista que estejam em maior contato com a comunidade, podendo identificar de forma mais próxima e facilitadora a realidade vivenciada nos lares. É a partir dessa perspectiva que o presente estudo contou com a colaboração desses profissionais para a identificação e conhecimento dos casos de violência e maus-tratos contra idosos na cidade de Parnaíba-Piauí.

A temática da velhice no âmbito da Psicologia Social pouco foi estudada até o século passado. No entanto, pesquisas científicas relacionadas a este fenômeno social vêm crescendo significativamente nas últimas décadas, demonstrando a importância da compreensão desse objeto a partir de uma ótica biopsicossocial. Dessa forma, o presente estudo objetiva verificar as Representações Sociais (RS) da violência na velhice entre profissionais de saúde da equipe de Estratégia de Saúde da Família (ESF), com o escopo de disponibilizar aos profissionais inseridos no ESF mecanismos de intervenção, identificação e prevenção aos casos de violência que eventualmente venham a vislumbrar na sua prática profissional (Araújo et al., 2012; Araújo, Rocha, \& Cruz, 2012; Fortes-Burgos, 2010; Ministério da Saúde, 2008).

As RS como forma de conhecimento elaborado e compartilhado socialmente, bem como sistemas de interpretação, governam nossas relações com o mundo que determina e organiza nossas condutas e comunicações sociais, interferindo em processos como o desenvolvimento individual e coletivo e nas transformações pessoais (Jodelet, 2001). Segundo Moscovici (2003), a Teoria das RS constitui-se num instrumento de estudo particularmente importante nas relações em que os aspectos simbólicos são determinantes das condutas, práticas e dos comportamentos (Moscovici, 2003).

A teoria das RS passa a considerar os posicionamentos dos indivíduos frente a objetos cotidianos, não mais como reações singulares, e sim como uma reelaboração de um conjunto de saberes compartilhado nos grupos. As RS são produzidas pelas interações e comunicações no interior de grupos sociais, refletindo nos assuntos que dizem respeito ao objeto do seu cotidiano. São justamente as teorias criadas pelos grupos, denominadas de teorias do senso comum, o principal objeto de estudo das representações. Para que as RS aconteçam, é necessário que ocorram dois processos que se modelam através dos fatores sociais: a objetivação e a ancoragem (Jodelet, 2001; Moscovici, 2003).

A objetivação trata da maneira como os elementos constituintes da representação são organizados e sobre o caminho que esses levam até adquirirem a materialidade. Materialidade trata-se de como o indivíduo torna a realidade vivida, que antes não fora observada, como algo natural e real a si. No processo de ancoragem, as RS podem preceder ou dar sequência ao processo de objetivação. No caso de preceder a objetivação, a ancoragem utiliza ou se apropria das informações recorrendo às referências, ou seja, utilizase de experiências ou esquemas já estabelecidos para refletir sobre o objeto da representação. No caso de apresentar-se como sequência à objetivação, a ancoragem funciona como uma função social das representações, procurando compreender os elementos representados no processo de construção das relações sociais (Moscovici, 2003).

Segundo Jodelet (2001), O processo de ancoragem é complexo, levando a uma produção de transformações nas representações já constituídas, isto é, "o processo de ancoragem é, a um tempo, um processo de redução do novo ao velho e reelaboração do velho tornando-o novo" (2001, p. 363). Nessa perspectiva, a função essencial das RS, para aqueles que representam, "é tornar familiar algo não familiar, ou a própria não-familiaridade" (Moscovici, 2003, p. 54). Essa função relaciona-se com a tentativa de representar uma realidade pouco conhecida a partir do que se sabe dela (Jodelet, 2001; Moscovici, 2003).

Pode-se considerar que representações da "violência na velhice" levam a diferentes compreensões da problemática violência e, consequentemente, há diferentes propostas e medidas para seu enfrentamento, visto que as representações da "violência na velhice", construídas e compartilhadas socialmente, estariam intervindo no processo de enfrentamento da 
problemática na medida em que constituem um fator determinante da sua compreensão.

Justamente pela emergência do tema, bem como pela gravidade em que se apresenta o panorama mundial da violência contra o idoso, é que urge a necessidade de investigações que proporcionem melhorias na saúde e qualidade de vida de acordo com essa faixa etária (Araújo \& Lobo Filho, 2009; Neri, 2009). Diante disso, torna-se relevante social e academicamente identificar e comparar as RS da violência na velhice entre Agentes Comunitários de Saúde (ACSs) e os Profissionais de Saúde inseridos no Programa Saúde da Família (PSF), uma vez que essas representações podem interferir na prática desses profissionais no enfrentamento e prevenção da violência contra pessoas idosas.

\section{Método}

\section{Tipo de estudo}

Trata-se de um estudo com desenho ex-postfacto de tipo transversal (Montero \& León, 2007).

\section{Locus de investigação}

O estudo foi realizado nas equipes do PSF junto aos ACS's e Profissionais de saúde (enfermeiros, médicos e odontólogos) da secretaria de saúde do município de Parnaíba-Piauí.

\section{Participantes}

Participaram da pesquisa 100 atores sociais, sendo 50 ACSs e 50 profissionais de saúde (11 médicos, 10 odontólogos e 29 enfermeiros) com idade variando entre 25 e 60 anos com média de idade de 36,84 anos, sendo $59 \%$ do sexo feminino e $41 \%$ do sexo masculino, visto que $21 \%$ dos participantes residem com idosos. A maioria dos ACSs entrevistados (68\%) possui ensino médio completo; já com relação aos profissionais de saúde, apenas $40 \%$ possui pós-graduação. Faz-se necessário mencionar que tal escolha ocorreu com o intuito de comparar as RS acerca da violência na velhice entre os ACSs e os profissionais de saúde, considerando que as diferenças grupais podem contribuir para a construção de RS ancorada no saber prático e pertença grupal. Os incluídos na pesquisa dispunham de livre escolha para participar ou não do presente estudo.

\section{Instrumentos}

Foram utilizados para a realização da pesquisa um questionário sociodemográfico e uma entrevista estruturada. O Questionário sociodemográfico apresentava itens referentes à identificação dos participantes, definindo o seu perfil (idade, sexo, estado civil, tempo de atuação na unidade e experiência e/ou convívio com idosos). A Entrevista Estruturada foi composta por quatro perguntas norteadoras versando sobre violência contra a pessoa idosa, enfatizando as representações e as percepções dos mesmos no tocante a tal aspecto. Essas foram: (1) Como você observa a violência contra a pessoa idosa? (2) Você já identificou na sua prática profissional algum caso de violência contra o idoso? (Caso sim, mencione os tipos). (3) Como você avalia o papel desempenhado pelos profissionais de saúde diante da violência contra os idosos? (4) O que você acredita que poderia ser feito para prevenir casos futuros de violência contra a pessoa idosa?

\section{Procedimentos}

\section{Coleta de dados}

Diante do processo de realização do estudo, foi mantido um contato prévio com a Secretaria Municipal de Saúde de Parnaíba-PI mediante um ofício apresentado à coordenadora do ESF no município com o intuito de adquirir autorização para a aplicação dos instrumentos. Posteriormente, foi mantido o contato com os ACSs e os Profissionais de saúde tendo em vista a disponibilidade dos mesmos em participarem de forma espontânea da pesquisa, garantindo-lhes o anonimato e a confiabilidade das suas respostas, mostrando que essas seriam analisadas no seu conjunto.

A aplicação do instrumento foi realizada por dois pesquisadores previamente treinados e qualificados. Os ACSs e Profissionais de saúde previamente receberam dos aplicadores as devidas instruções para responder às questões, assinando um Termo de Consentimento Livre e Esclarecido. Posteriormente, foi realizada a entrevista estruturada e o questionário sociodemográfico preenchido em seguida. O tempo médio de aplicação foi de 20 minutos para cada participante. A presente pesquisa foi apreciada e aprovada pelo Comitê de Ética em Pesquisa da Universidade Federal do Piauí com parecer $\mathrm{n}^{\circ}$ 0200.045.000-09.

\section{Análise dos dados}

Para análise dos dados apreendidos através da entrevista, foi utilizada ALCESTE (Análise lexical por contexto de um conjunto de segmentos de textos) em sua versão 4.5, a qual foi desenvolvida na França por Reinert (1986, 1990). Tal programa, além de 
proporcionar uma análise lexical quantitativa que valoriza a palavra como unidade, também oferece uma contextualização geral da entrevista. Cada entrevista é constituída de conteúdos semânticos formando um banco de dados analisados. Foi realizada uma analise hierárquica descendente permitindo a análise das raízes lexicais e oferecendo os contextos em que as classes estão inseridas de acordo com o segmento de textos do banco de dados (Camargo, 2005).

Inicialmente foi construído um banco de dados das entrevistas seguindo o modelo proposto por Camargo (2005). Para a formatação de bancos de dados foi realizado um único arquivo digitado no Word for Windows 2003, salvo no tipo texto-txt. As linhas de comando sempre digitadas antes de cada conteúdo semântico da entrevista possuem o objetivo de separar cada Unidade de Contexto Inicial (UCI), que diz respeito às respostas que os atores sociais mencionaram frente à pergunta norteadora. Nas linhas de asteriscos foram digitadas as variáveis descritivas (idade, sexo, profissão, estado civil, residir com idoso). Após a formatação do banco de dados, foi realizada a análise no software Alceste envolvendo quatro etapas: (a) Leitura do texto e cálculos dos dicionários; (b) Cálculos das matrizes de dados e classificação das UCEs; (c) Descrição das classes de UCEs; (d) Cálculos complementares.

\section{Resultados e discussões}

A análise dos resultados constituída pelo corpus de 100 unidades de contexto inicial (u.c.i.) ou entrevistas e processados pelo software Alceste apresentou uma divisão de corpus em 1618 unidades de contexto elementar (u.c.e.), contendo 7440 palavras, formas ou vocábulos distintos.

O dendograma 1 diz respeito à distribuição das três classes das Representações Sociais da Violência na Velhice apreendidas pelos ACS e Profissionais de Saúde inseridos no PSF.

Observa-se no dendograma o título de cada uma das classes, seguido pelo número de u.c.e que a compõe, a descrição da classe, bem como as variáveis descritivas e as palavras de maior associação com a referida classe, levando-se em consideração o coeficiente alcançado no teste de associação $\mathrm{X}^{2}$.

Destaca-se que as RS da violência na velhice no Dendograma 1 apresentado estão estruturadas em três classes, nomeadas: Concepções acerca dos maus-tratos na velhice, Cuidados inerentes à velhice, O papel dos profissionais referente à prevenção. Serão discutidas a partir das u.c.e. as classes estruturadas a seguir.
Classe 1: Concepções acerca dos maus-tratos na velhice

As informações que compõem as RS dos maus-tratos conforme as entrevistas incluem atos ou omissões que produzem dano ou perigo para a saúde do idoso, incluindo a negação de alimentos, de assistência médica, de vestuário e dano físico ou mental. A classe 1 é composta por 230 u.c.e., que constituem 35,28\% de explicação do total, tornando-se significativa quanto às representações encontradas de uma maneira geral. Considerando as variáveis descritivas, pode caracterizar-se, em sua maioria, por profissionais de saúde - médicos - na faixa etária entre 31 a 40 anos.

Nessa classe, percebe-se a predominância de conteúdos que se referem às definições de maus-tratos sofridos pelos idosos. As palavras que obtiveram maior associação com a classe foram: família, respeito, amor, sociedade, própria, mau-trato, filho, falta. Os conteúdos lexicais apreendidos nessa classe pelos profissionais referem-se ao abandono sofrido pelos idosos numa frequência bem maior e numa dimensão muito mais grave. Conforme o relato a seguir:

A violência contra a pessoa idosa se dá na forma física, não só agressão, mas como na falta de alimentação adequada levando à desnutrição, baixa imunidade. Falta de condições favoráveis de moradia favorecendo acidentes domésticos e até expostos às catástrofes naturais, agressão moral de sentir-se incapaz de sustentar-se e à sua família e principalmente o abandono pela sociedade e às vezes na família ... Ainda deixa muito a desejar, pois não há uma capacitação adequada para isto, então a maioria dos profissionais deixa isto passar despercebido. Diante dessa linha de pensamento acredito que necessita de investimentos nas gestões nos aspectos economicos e sociais e também em uma conscientização cultural para todos nós sabermos valorizar nossos idosos. (Entrevista 80 )

Os relatos estão intimamente atrelados ao que é comum aos idosos que vivem com seus familiares conforme seu grau de dependência, tornando-secadavez mais necessários uma avaliação e um entendimento da dinâmica das famílias por uma equipe multidisciplinar. Machado e Queiroz (2006) destacam que, no contexto de maus-tratos e negligência contra a pessoa idosa no ambiente familiar, há sempre os fatores de risco, como a dependência do idoso fragilizado e do agressor dependente da vítima, a história de violência familiar, o estresse do cuidador, o isolamento social, a presença de alcoolistas entre os membros da família e outros. Dessa maneira, faz-se necessária a presença de uma família cuidadora atenciosa e saudável vivenciando uma dinâmica intrafamiliar livre de fatores de risco de 
violência (Araújo et al., 2012; Araújo, Rocha, \& Cruz, 2012; Minayo, 2007; Pinho et al., 2009).

Faz-se pertinente também questionar até que ponto os familiares são responsáveis pelos seus idosos, pois nota-se um descompasso entre as responsabilidades da família, da sociedade e do Estado. No entanto, é importante salientar que o núcleo familiar é o principal responsável pelo bemestar do idoso, cabendo ao Estado estabelecer leis, normas e regras para combater qualquer tipo de abuso contra o individuo na sociedade, como salienta o artigo $3^{\circ}$ da Constituição da República Federativa do Brasil (1998). A família, sendo um sistema que conjuga valores, crenças, práticas e conhecimentos, forma um modelo explicativo de saúde-doença, através do qual desenvolve sua dinâmica de funcionamento, promovendo a saúde, prevenindo e tratando a doença de seus membros (Fortes-Burgos, 2010; Santos et al., 2007).

Outro fato que merece destaque nessa classe concerne à questão dos maus-tratos que ocorrem dentro do ambiente familiar, podendo identificar que essa ocorrência desde a antiguidade assumiu diferentes conotações, chegando aos dias de hoje com alta frequência, como pode ser verificado nas u.c.e. mais típicas dessa classe:

A violência existe tanto física quanto verbal, principalmente por parte dos familiares ... é uma situação delicada que muitas vezes requer a ajuda do serviço social não dependendo apenas do PSF tendo casos que envolvem até a justiça. Respeitar mais o idoso. (Entrevista 58)

Faleiros (2007) destaca que o segredo ou conluio familiar faz com que os idosos não denunciem seus agressores, isto devido à vinculação, confiança, cumplicidade e também ao autoritarismo do agressor. Em muitos casos, o medo da vítima em quebrar a confiança estabelecida pela família é o que mais faz o idoso hesitar em realizar uma denúncia.

Do ponto de vista cultural, é razoável afirmar que não há registros antropológicos que não possuam atos de violência em suas relações interpessoais. Entre eles, a violência intrafamiliar, configurando-se numa construção biopsicossocial e histórico-cultural que se expressa ganhando força nas disputas de poder que são direcionados aos grupos minoritários como mulheres, crianças, adolescentes, homossexuais, índios e idosos (Araújo et al., 2012; Araújo \& Lobo Filho, 2009; Araújo, Rocha, \& Cruz, 2012; Neri, 2009; Saraiva \& Coutinho, 2012).

Ainda em relação aos maus-tratos, destacamse a limitação que os profissionais da saúde sofrem para enfrentar tal problemática quando não se tem a colaboração da família, que, ao contrário, acaba negando qualquer tipo de agressão que o idoso possa estar sofrendo: “como consequência de uma sociedade violenta e que não valoriza o indivíduo pelo que ele representa ... limitado, pois a família pode negar tudo para o poder público quando é questionada e depois quando vamos embora os maus-tratos continuam" (Entrevista, 83).

Nesse sentido, o "silêncio" continua representando uma das grandes barreiras para identificação dos maus-tratos contra o idoso, visto que esses casos são vistos como algo natural, "resolvidos" pela própria família (Minayo, 2007). O único momento em que essa realidade muda é quando, em raras situações, esta vítima, cansada dos abusos e maus-tratos, decide romper este silêncio e denunciar os verdadeiros agressores (Araújo et al., 2012; Araújo, Rocha, \& Cruz, 2012; Faleiros, 2007).

Verifica-se, dessa forma, na classe 1, que os conteúdos da análise hierárquica tornam nítida a constatação de que a situação de maus-tratos é vislumbrada apenas quando ela apresenta resultados mais drásticos, como traumas e mortes. A ligação direta entre as classes 1 e 3 corrobora para uma reflexão crítica, bem como subsidia movimentos de debates que procurem identificar a ocorrência de maus-tratos, no sentido de promover programas de prevenção e valorização da condição de vida do idoso (FortesBurgos, 2010; Neri, 2009).

\section{Classe 2: Cuidados inerentes à velhice}

A segunda classe da análise hierárquica aqui aplicada foi estruturada com 188 u.c.e., representando $28,83 \%$ do total das 100 entrevistas. Ressalta-se que esta é a classe de menor poder explicativo do dendograma 1 . No referente às variáveis descritivas, a classe 2 foi formada por profissionais que residem com o idoso (58\%), do sexo masculino e inseridos em um intervalo de idade de 31 a 40 anos.

As palavras de maior associação a esta classe referem-se aos cuidados inerentes à velhice, a saber: preciso, melhor, acho, observo, faz. Percebem-se nesse discurso, de acordo com as unidades de contexto elementar (u.c.e.), os conteúdos semânticos que mais caracterizam esta classe: "os idosos não tem voz nem vez nessa nossa sociedade ... são desvalorizados, tidos como pessoas que não podem contribuir para a sociedade ... acho que não estamos preparados o suficiente para trabalhar com eles" (Entrevista 3).

Os dados da pesquisa podem ser observados de forma consonante com a literatura quando atenta-se 
para os relatos sobre a desvalorização e o preconceito sofrido por parte dos idosos. A sociedade em muitos casos reproduz a ideia de que o indivíduo só vale o quanto produz. Dessa forma, os mais velhos passam a ser considerados como "pesos mortos ou inúteis" (Araújo et al., 2012; Araújo, Rocha, \& Cruz, 2012; Minayo, 2007; Saraiva \& Coutinho, 2012). Diante dos fatos, verifica-se uma necessidade de elaboração de planos de cuidados para os idosos maltratados, visando seu bem-estar físico e mental.

Pode-se verificar também, nessa classe, uma contribuição muito significativa dos profissionais envolvidos, os quais demonstraram preocupação com os cuidados necessários para obter uma velhice saudável. Por outro lado, eles necessitam de mais preparo para lidar com essa questão. Sendo assim, é importante e urgente a junção de forças para combater essa problemática, visando definir políticas públicas e investir no envolvimento de instituições da comunidade que possam ser capazes de auxiliar a família a entender e a cumprir suas obrigações com os idosos (Araújo \& Lobo Filho, 2009; Fortes-Burgos, 2010; Neri, 2009; Saraiva \& Coutinho, 2012).

\section{Classe 3: O papel dos profissionais referente à prevenção}

Finalmente, a terceira classe da análise hierárquica que foi empregada envolve $35,89 \%$ do total, concluindo 234 unidades de contexto elementar. Essa terceira RS exibe um alto poder explicativo através da sua representatividade na análise semântica. As variáveis descritivas predominantes nessa classe são os profissionais dentistas com idade entre 51 a 66 anos e não residentes com idosos.

As RS nessa classe organizaram-se em torno do papel dos profissionais ancoradas na prevenção, a saber: idoso, trabalho, saúde, lei, importante, educação, dever. Pode-se perceber, conforme as unidades de contexto elementar (u.c.e.), que o que mais se caracteriza nessa classe diz respeito aos conteúdos semânticos a seguir:

tudo na vida são princípios, se você não tem uma boa educação quando criança não terá quando for adulto e consequentemente surgirá com o tempo o que vemos hoje, os comportamentos violentos dos jovens ... todo profissional tem os bons e os ruins, os que enfrentam as dificuldades da violência e os que não tem coragem ou vontade e enfrentar. (Entrevista 98)

Nesse agrupamento, pode-se verificar que as RS foram objetivadas no aspecto referente à importância do papel exercido pelo profissional de saúde no que tange à identificação e à notificação de maus-tratos, além de outras ocorrências em caso de suspeita de violência contra o idoso.

Segundo o Ministério da Saúde (2008), as agressões que chegam ao SUS são principalmente as explícitas, existindo ainda outros tipos. O contexto da violência que envolve o idoso fragilizado e dependente representa um problema social de grande dimensão que atinge toda a sociedade. Entende-se que é necessário discutir estratégias para proteger os idosos contra a ocorrência da violência intrafamiliar. O enfrentamento a este fenômeno envolve profissionais de várias áreas de atuação, requerendo, por conseguinte, uma efetiva mobilização do governo e da sociedade civil (Araújo et al., 2012; Araújo, Rocha, \& Cruz, 2012; FortesBurgos, 2010; Ministério da Saúde, 2008; Santos et al., 2007).

Observa-se também que a maioria dos profissionais de saúde não se sente capacitada para identificar e encaminhar devidamente os casos de maus-tratos contra o idoso. Muitas vezes, a situação é denunciada, no entanto, ao retornarem às suas casas, são maltratados novamente, gerando medo e apreensão, conforme relato a seguir:

o desempenho às vezes fica muito aquém, já que os idosos têm que voltar a viver novamente com os agressores ... uma politica voltada não só contra a violência, mas voltada para o bem-estar da pessoa idosa, como abrigos de boa qualidade, cuidados com a saúde periódicos, boa alimentação e lazer. (Entrevista 97)

Os profissionais de saúde apresentam dificuldades na elaboração da ficha de notificação ao perceberem sinais de violência e sentem-se despreparados para o manejo dessas situações. O GEAVIDAS (Grupo de Estudos em Atenção à Vítima de Violência Doméstica e Agressão Sexual) do Hospital das Clínicas da Faculdade de Medicina de Ribeirão Preto-SP implantou durante o ano de 2003, em parceria como os núcleos de Saúde da Família (NSF), a ficha de notificação de casos confirmados ou suspeitos de violência, maus-tratos e abuso sexual contra crianças, adolescentes e idosos para oficializar nos Serviços de Saúde de Ribeirão Preto. A ficha de notificação objetiva identificar como destaque casos de violência doméstica, dando ênfase ao fenômeno através dos serviços de vigilância epidemiológica do município, surgindo, a partir daí, mobilizações das políticas públicas necessárias para a implantação de equipamentos e capacitação dos profissionais da área da saúde (Bava, Cabrera, \& Domingo, 2003).

Gonçalves e Ferreira (2002) destacam a importância da notificação por ser um instrumento 
no combate à violência que produz benefícios para os casos singulares e que serve de controle epidemiológico da violência. Assim sendo, legalmente o profissional de saúde possui o dever de notificar os casos suspeitos ou confirmados de violência e desempenhar um papel vital nessa área: "existe um pouco de dificuldade por parte dos profissionais para identificar e denunciar os casos de violência contra idosos, pois há muita negligência em relação a isso" (Entrevista 96).

Nesse sentido, torna-se cada vez mais necessária a capacitação dos profissionais de saúde visando a identificar e intervir com competência na violência em geral sofrida, muitas vezes no silêncio, pelos idosos, resgatando sua dignidade. No tocante aos profissionais da área de saúde, destaca-se a importância do papel desempenhado por eles. $\mathrm{Na}$ prática diária e direta com os idosos usuários de serviços de saúde, cabe ao profissional de saúde saber investigar e identificar os casos de violência e maus-tratos, agir coordenadamente com outros profissionais e, com isso, traçar intervenções eficazes para cada caso (Araújo et al., 2012; Araújo, Rocha, \& Cruz, 2012; Minayo, 2007; Pinho et al., 2009).

São escassas as fontes de dados confiáveis e expressivas a respeito da violência contra os idosos. Isso se deve ao fato oculto pelas famílias e ao despreparo de profissionais de saúde em não focalizar seu olhar clínico para a detecção do problema. Não existe, ainda, uma consciência coletiva de denúncia dos abusos, assim como não há serviços destinados à receptação de tais denúncias (ex.: SOS idosos).

Percebe-se que a prevenção do abuso, a identificação e o encaminhamento correto dos casos são pontos primordiais para que o respeito e a valorização da pessoa idosa sejam restabelecidos, de forma que ela possa usufruir de uma velhice saudável, sem temor, opressão ou tristeza (Araújo et al., 2012; Araújo, Rocha, \& Cruz, 2012; Fortes-Burgos, 2010; Machado \& Queiroz, 2006; Neri, 2009; Pinho et al., 2009; Saraiva \& Coutinho, 2012).

Urge, portanto, a necessidade de que os profissionais de saúde debatam a temática para que possam ser criadas propostas de intervenção visando a melhorias no diagnóstico de ocorrência de violência contra o idoso e à ideologia social da família. Denotase, na presente investigação, que as RS da violência contra idosos, elaboradas pelos Profissionais de Saúde juntamente com os ACSs, foram ancoradas nos seus aspectos psicossociais e histórico-culturais da velhice. Desse modo, pôde-se perceber, no conjunto de dados apreendidos, que tem sido o âmbito familiar identificado como o local privilegiado para a expressão da violência contra a pessoa idosa. Por outro lado, foi verificada a importância do papel desempenhado pelo profissional da saúde bem como das ações estratégicas da ESF na identificação, combate e prevenção da violência na velhice.

\section{Considerações finais}

A análise dos conteúdos permitiu verificar a forma como os atores sociais (ACSs e Profissionais de Saúde) representaram socialmente a violência contra a pessoa idosa, associando-a tanto à falta de preparo por parte do profissional de saúde quanto à falta de preparo do familiar e/ou cuidador.

Verifica-se que há uma grande dificuldade na aplicação das leis de proteção ao idoso, determinadas pelo código penal (1984). Por exemplo, o início de um processo penal no caso de violência intrafamilar na velhice, que só pode ser aberto caso o idoso apresente a queixa contra o parente (artigo 182). É nesse ponto que o Estado precisa apresentar políticas de apoio, estendendo os limites da assistência através da implementação das ações que estão previstas no Estatuto do Idoso, no Plano de Ação para Enfrentamento da Violência contra a Pessoa Idosa (PAEVPI) e em outros dispositivos. Trata-se da criação e extensão de programas de assistência, como centros de convivência, melhor acessibilidade e atendimento pelo SUS, centros de cuidados diurnos, entre outras providências que visem a facilitar a vida do idoso e de seus familiares, diminuindo, por consequência, os riscos de violência.

Espera-se que este trabalho possa fornecer subsídios e orientações para discussão e reflexão acerca das práticas dos profissionais de saúde e ACS, no que diz respeito à violência contra o idoso, podendo estes resultados ser utilizados em pesquisas futuras que pretendam construir medidas para o constructo em apreço. Novas investigações são sugeridas para que se possa avaliar o conhecimento psicossocial elaborado acerca da violência e maus-tratos na velhice, tendo em vista como participantes os próprios idosos (vítimas da violência), agentes de violência, trabalhadores de saúde e de serviços sociais, gestores públicos e o terceiro setor envolvidos com as questões gerontológicas.

Fazem-se também necessários mecanismos de incentivo para as denúncias de violência sofrida pelos idosos, Delegacias e Promotorias da Defesa da Pessoa Idosa, instrumentos como o Disque Idoso e outros que incentivem as notificações oficiais de maus-tratos, oferecendo apoio psicossocial aos idosos violentados. Essas são iniciativas práticas e eficazes que poderiam ser, dentro das condições de cada realidade, multiplicadas. 


\section{Referências}

Araújo, L. F., Amaral, E. B., Sá, E. C. N., Azevedo, R. L. W., \& Lobo Filho, J. G. (2012). Violência contra a pessoa idosa: representações sociais entre adolescentes do Arquipélago de Fernando de Noronha-PE. Psicologia \& Sociedade, 24(1), 104-111.

Araújo, L. F. \& Lobo Filho, J. G. (2009). Análise psicossocial da violência na velhice. Psicologia: Reflexão e Crítica, 22(1), 153-160.

Araújo, L. F., Rocha, R. A., \& Cruz, E. A. (2012). Estudo psicossocial daviolência na velhice: o que pensam os agentes comunitários e profissionais de saúde? Psicologia: Teoria e Prática, 14(1), 1-20.

Bava, M. C .G. C., Cabrera, C. C., \& Domingo, N. A. M. (2003). Violência doméstica no Municipio de Ribeirão Preto: dando visibilidade para a construção de políticas públicas - Relato de Experiência. Trabalho apresentado no Congresso da Associação de Psiquiatria e Saúde Pública de Ribeirão Preto, 8. Acesso em 07 de abril, 2010, em http://www.fmrp.usp.br/ rms/index.php?pg=base \& coduser $=12 \& \operatorname{codpag}=349$

Camargo, B. V. (2005). ALCESTE: Um programa informático de análise quantitativa de dados textuais. In A. S. P. Moreira, J. C. Jesuíno, \& B. V. Camargo (Orgs.), Perspectivas teórico-metodológicas em representações sociais (pp. 511539). João Pessoa: EdUFPB.

Constituição Federativa do Brasil de 1988 (18 a ed.). (1998). São Paulo. Saraiva.

Faleiros, V. P. A. (2004). Violência na velhice. O Social em questão, 8(11), 7-30.

Faleiros, V. P. (2007). Violência contra a pessoa idosa ocorrências, vítimas e agressores. Brasília, DF: Universa.

Fortes-Burgos, A. C. G. (2010). Condições de risco biológico e psicossocial, recursos psicológicos e sociais e funcionalidade em idosos residentes na comunidade. Tese de Doutorado, Faculdade de Educação, Universidade Estadual de Campinas, Campinas, SP.

Gonçalves, H. S. \& Ferreira, A. L. (2002). A Notificação da violência intrafamiliar contra crianças e adolescentes por Profissionais de saúde. Cadernos de Saúde Pública, 18(1), 265-279.

Instituto Brasileiro de Geografia e Estatística - IBGE. (2008). Pesquisa Nacional por Amostra de Domicilios [CD-ROM]. Rio de Janeiro: Autor.

Jodelet, D. (2001). As representações sociais. Rio de Janeiro: EdUERJ.

Machado, L. \& Queiroz, Z. V. (2006). Negligência e MausTratos. In E. V. Freitas (Org.), Tratado de geriatria $e$ gerontologia (pp. 1152-1159). Rio de Janeiro: Guanabara Koogan.

Minayo, C. S. (2007). A inclusão da violência na agenda da saúde: Trajetória histórica. Ciência \& Saúde Coletiva, 11(1), 1259-1267.

Ministério da Saúde. Secretaria de Políticas de Saúde. (2008). Política Nacional de Redução da Morbimortalidade por Acidentes e Violência. Revista Saúde Pública, 18(1). Acesso em 18 de outubro, 2009, em http://bvsms.saude.gov.br/bvs/ periodicos/rev_epi_vol18_n1.pdf

Ministério da Saúde. Secretaria de Atenção à Saúde. Departamento de Atenção Básica. (2009). Envelhecimento e saúde da pessoa idosa. Brasília, DF: Autor.
Montero, I. \& León, O. (2007). A guide for naming research studies in psychology. International Journal of Clinical and Health Psychology, 7(3), 847-862.

Moscovici, S. (2003). Representações sociais: investigações em psicologia social. Petrópolis, RJ: Vozes.

Neri, A. L. (2009). Autonomia e independência. In M. E. Guariento \& A. L. Neri (Orgs.), Assistência ambulatorial ao idoso (pp. 327-334). Campinas, SP: Alínea.

Pinho, M. X., Custódio, O., \& Makdisse, M. (2009). Incidência de depressão e fatores associados em idosos residentes na comunidade: Revisão da literatura. Revista Brasileira de Geriatria e Geriatria, 12(1), 123-140.

Reiniert, M. (1986). Un Logiciel d'analyse lexicale: ALCESTE. Les Cahiers de l'analyse des Données, 4, 471-484.

Reiniert, M. (1990). Alceste - Une methologie d'analyse dês donnees textualles et une application: A. G. de Neval. Bulletin de Méthodologie Sociologique, 28, 24-54.

Santos, A. C. P. O., Silva, C. A., Carvalho, L. S., \& Menezes, M. R. A. (2007). Construção da violência contra idosos. Revista Brasileira de Geriatria e Gerontologia, 10(1), 115-127.

Saraiva, E. R. \& Coutinho, M. P. L. (2012). A difusão da violência contra idosos: um olhar psicossocial. Psicologia \& Sociedade, 24(1), 112-121.

Recebido em: 12/06/2010

Revisão em: 02/04/2012

Aceite em: 23/04/2012

Ludgleydson Fernandes de Araújo é Psicólogo, Doutorando em Psicologia pela Universidad de Granada, Espanha. Mestre em Psicologia Social e Especialista em Gerontologia pela UFPB. Professor Assistente III da Universidade Federal do Piauí. Endereço: Universidade Federal do Piauí/ Departamento de Psicologia/ Campus de Parnaíba, Av. São Sebastião, 2819, Parnaíba/PI, Brasil CEP. CEP: 64202-020. Email: ludgleydson@yahoo.com.br

Edilene Alves da Cruz é Bolsista de Iniciação Científica Voluntária, Graduanda em Psicologia pela Universidade Federal do Piauí - UFPI (Campus Ministro Reis Velloso Parnaíba-PI). Email: edilenealvesphb@hotmail.com

Romulo Araujo da Rocha é Bolsista de Iniciação Científica Voluntária, Graduando em Psicologia pela Universidade Federal do Piauí - UFPI (Campus Ministro Reis Velloso Parnaíba-PI). Email: romulorocha@ymail.com

\section{Como citar:}

Araújo, L. F., Cruz, E. A., \& Rocha, R. A. (2013). Representações sociais da violência na velhice: estudo comparativo entre profissionais de saúde e agentes comunitários de saúde. Psicologia \& Sociedade, 25(1), 203-212. 
Araújo, L. F., Cruz, E. A., \& Rocha, R. A. Representações sociais da violência na velhice: estudo comparativo...

Dendograma 1: Distribuição das classes nas representações sociais da velhice - Agentes Comunitários de saúde (ACS's) e Profissionais da saúde

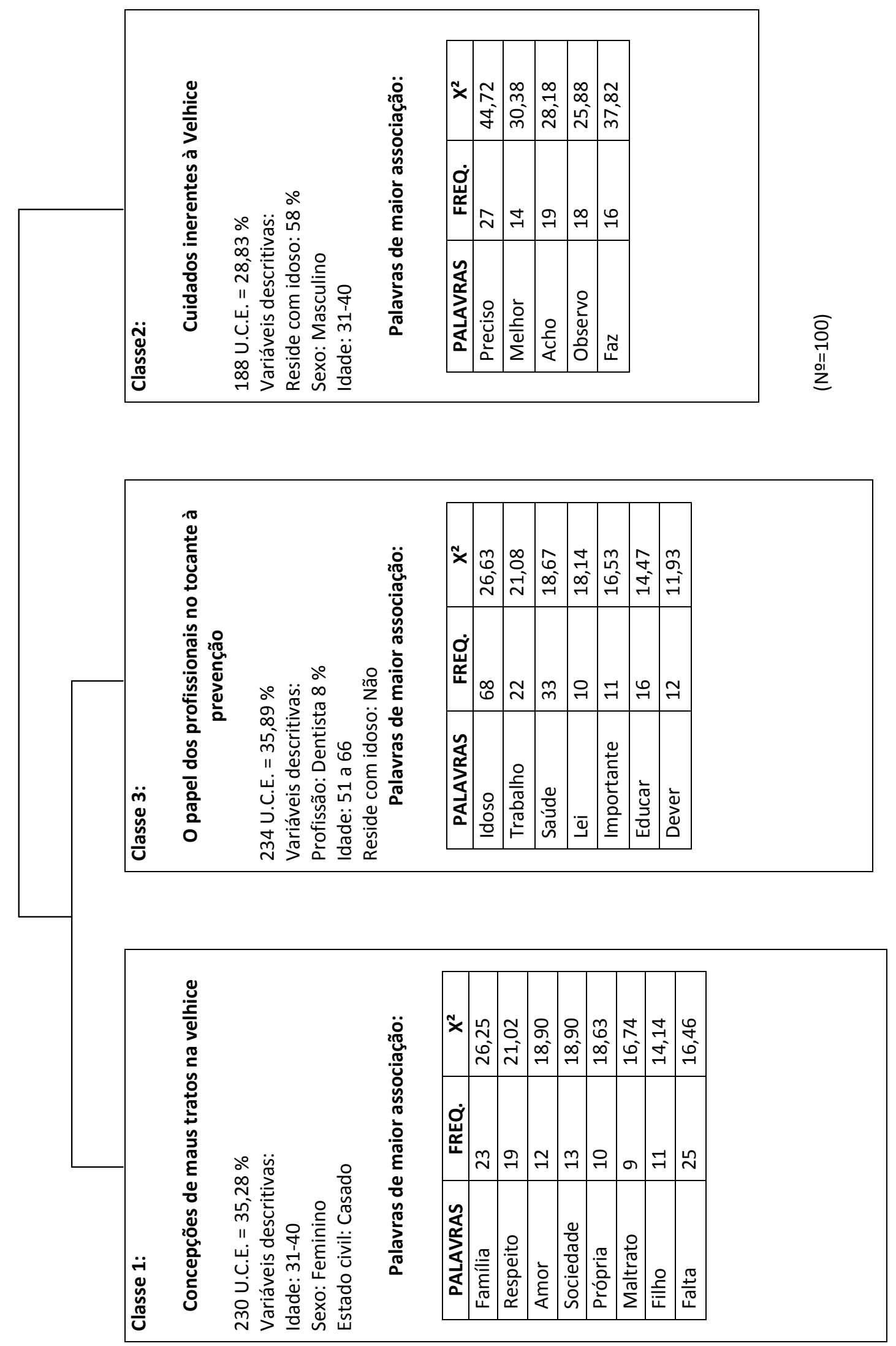

